\title{
2008/1
}

Evaluating the impact of average cost based contracts on the industrial sector in the European emission trading scheme

Giorgia Oggioni and Yves Smeers 


\title{
CORE DISCUSSION PAPER
}

$2008 / 1$

\section{Evaluating the impact of average cost based contracts on the industrial sector in the European emission trading scheme}

\author{
Giorgia OGGIONI ${ }^{1}$ and Yves SMEERS ${ }^{2}$
}

January 2008

\begin{abstract}
The inception of the Emission Trading System in Europe (EU-ETS) has made power price more expensive. This affects the competitiveness of electricity intensive industrial consumers and may force them to leave Europe. Taking up of a proposal of the industrial sector, we explore the possible application of special contracts, based on the average cost pricing system, which would mitigate the impact of $\mathrm{CO}_{2}$ cost on their electricity price. The model supposes fixed generation capacities. A companion paper treats the case with capacity expansion.

We first consider a reference model representing a perfectly competitive market where all consumers (households and industries) are price-takers and buy electricity at the short-run marginal cost. We then change the market design assuming that large industrial consumers pay power either at a single or at a nodal average cost price.

The analysis of these problems is conducted with simulation models applied to the Northwestern European market. The equilibrium models developed are implemented in the GAMS environment.

Keywords: average cost pricing, complementarity conditions, EU-ETS, Northwestern Europe market.

AMS Classification: 46N10, 90C33, 91B24, 91B42

\footnotetext{
${ }^{1}$ Universita degli Studi di Bergamo, Italy and CORE, Université catholique de Louvain, Belgium. Email: giorgia.oggioni@unibg.it

2 Tractebel, Department of Mathematical Engineering and CORE, Université catholique de Louvain, Belgium. E-mail: yves.smeers@uclouvain.be. The author is also member of ECORE, the newly created association between CORE and ECARES.
}

This work has been supported by PRIN 2006, Generalized monotonicity: models and applications, Italy. National Responsible: Prof. E. Allevi. We wish to thank Thierry Bréchet and all the attendances of the Environmental Workshops for their comments and advices.

This paper presents research results of the Belgian Program on Interuniversity Poles of Attraction initiated by the Belgian State, Prime Minister's Office, Science Policy Programming. The scientific responsibility is assumed by the authors.
\end{abstract}




\section{Introduction}

Starting from January 2005, Member States of the European Union have introduced the European Emission Trading Scheme (EU-ETS hereafter) in order to curb $\mathrm{CO}_{2}$ emissions and tackle climate change. It is widely admitted today that the functioning of the EU-ETS should be improved. The degradation of the competitiveness of part of the European industry is progressively emerging as one of the possible consequences of the combination of the EU-ETS and the restructuring of the electricity sector. Electricity intensive industrial users strongly encourage the review of the ETS to mitigate its negative effects on their cost balance. This negative impact is twofold: industries need not only to abate emissions; they have also to pay a higher electricity price. This second effect results from the practice of the power sector to charge the $\mathrm{CO}_{2}$ costs into electricity prices. Industrial sectors can adapt to these cost increases by accepting a reduction of their profits or by increasing their product prices. They explain that this endangers their competitiveness on international markets. This will eventually imply a loss of sales and market share, especially for companies extremely exposed to foreign competition. Some studies (see $[2,9,11,13]$ ) show that the industrial sectors' exposure to the EU-ETS depends 1) on the industry's ability to pass the extra carbon cost to consumers, 2) on the international trade openness, 3) on the energy intensity and the possibility to abate carbon and, last, 4) on the allowance allocation method ${ }^{1}$. These factors vary with the industrial sector considered.

Large industrial consumers argue that this problem may force some of them to move part of their production activities in extra-Community countries where emission policies are less restrictive. This entails a serious loss of welfare for the European countries with an additional environmental damage due to more lenient norms in non-European countries (carbon leakage ${ }^{2}$ ). Large industrial consumers further claim that power producers exercise market power in order to maintain high electricity prices, a phenomenon that exacerbates the threat on competitiveness. A recent move from giant steel company Arcelor Mittal illustrates this $\mathrm{CO}_{2}$ problem. The company is refusing to re-open its blast furnace in Liège (Belgium) if it does not receive the necessary permits free. Lakshmi Mittal, the CEO of the company, asks Belgian public authorities to provide the carbon permits needed, otherwise he will move company's steel production outside Europe. In an interview given to the Belgian newspaper $L$ 'Echo, the CEO argues we must address the problem globally and not penalize the sector in Europe. The risk is a relocation of steel production to areas without $\mathrm{CO}_{2}$ constraints. He simply requires good conditions before investing in Europe ${ }^{3}$.

Under these conditions, industries explicitly ask for either special contracts whereby they can procure electricity at the average cost or special regulation that would prevent generators to embed the emission allowance price in the marginal cost of electricity.

\footnotetext{
${ }^{1}$ The allowance allocation method and the amount of allowances distributed affect operational costs. For instance, grandfathering lessens the cost imposed by the ETS system.

${ }^{2}$ Carbon leakage strongly depends on plants re-location. It measures the compensation of an industry's greenhouse gas reduction by an increase in the same industry's emissions in regions without carbon constraint.

3 Sources: L'Echo, 5/12/2007. Available at http://www.lecho.be/article/Mittal___sans_quotas_CO2__je_ne_relance_pas_Liege_.3434081.
} 
In this paper, we explore the first of these proposals, i.e. the possible introduction of special contracts based on the average cost pricing system, and we test to which extend they would heal some of the difficulties of the industry. We illustrate this issue by the means of small market simulations applied to a simplified electricity network of the Northwestern Europe (France, Germany, Belgium and The Netherlands). With the aim of investigating the implications of the carbon market on electricity prices and demand, we first simulate a perfectly competitive market where all consumers (households and industries) are price-takers and are assumed to pay an identical electricity price based on marginal costs. This represents the reference case. We then model two innovative pricing mechanisms. Assuming that industrial consumers can harness the financial means to acquire and operate part of base load power plants, we consider an alternative contractual organization whereby they pay the full cost of those installations and, hence, face average cost based prices. This new pricing policy is tested in two forms: there is a single average cost price in the first case; nodal average cost prices are introduced in the second one. Both scenarios imply segmenting the market and sharing the existing generation capacity between the two consumer groups in the sense that part of the generation capacity is fully dedicated to the large industrial consumers.

We find that the impact of average cost based prices on industrial consumers differs depending on their location and the price arrangement (single or nodal) applied. Moreover, the technology mix use to produce electricity plays a decisive role in industrial power prices.

\section{Input Data and Assumptions}

We conduct the analysis on a stylized representation of the Northwestern Europe of electricity market, where electricity is provided by eight generators ${ }^{4}$ and a fringe, which assembles the remaining small generators.

Generating companies are supposed to produce electricity by operating eight different technologies ${ }^{5}$. These are characterized by the existing capacities, the efficiencies and fuel costs (see Tables 14 and 15 in Appendix B). We use staircase marginal cost curves to represent the operation of generators. The marginal cost curves describe the (endogenously determined) merit order, which account emission factors and fuel costs of each plant. Moreover, we assume some renewable policy whereby TSO smooths out the variation of "wind" power and transforms it into a base load band. This policy has obviously a cost that we assume spread through a feed in tariff that all consumers pay. This type of policy is in place in some Member States such as Germany. It is introduced here as a proxy for policies favoring renewables and should obviously be modeled in more detail in a true case study.

The power system covers 15 nodes located in four countries (see Figure 1). They are connected by 28 arcs with limited capacity. The grid is modeled by DC load flow approximation and represented using a Power Transfer Distribution Factor $(P T D F)$ matrix provided by ECN (see [4] and Figure 1 for the values).

\footnotetext{
${ }^{4}$ E.ON Energie AG, Electrabel SA, Electricité de France, ENBW Energieversorgung BadenWürttemberg, Essent Energie Productie BV, Nuon, RWE Energie AG, Vattenfall Europe AG.

${ }^{5}$ Hydro (running-of-river plants), "wind", nuclear, lignite, coal, CCGT, other-gas and oilbased plants.
} 
Supply and demand are located at seven nodes: two in Belgium (Merchtem and Gramme), three in the Netherlands (Krimpen, Maastricht and Zwolle), one in Germany ("D") and, finally, one in France ("F"). The remaining German and French nodes are passive and are only used to transfer electricity. We consider two periods: winter peak and summer off-peak, measured in hours per year, with different durations. They are required to be identical in all countries included in the network. We state that the off-peak lasts seven months $(5,136 \mathrm{~h})$ and the peak the remaining five months $(3,624 \mathrm{~h})$. We fully acknowledge that this is not sufficient to get a good representation of the system. But it is sufficient to illustrate the phenomenon at work while keeping the model simple.

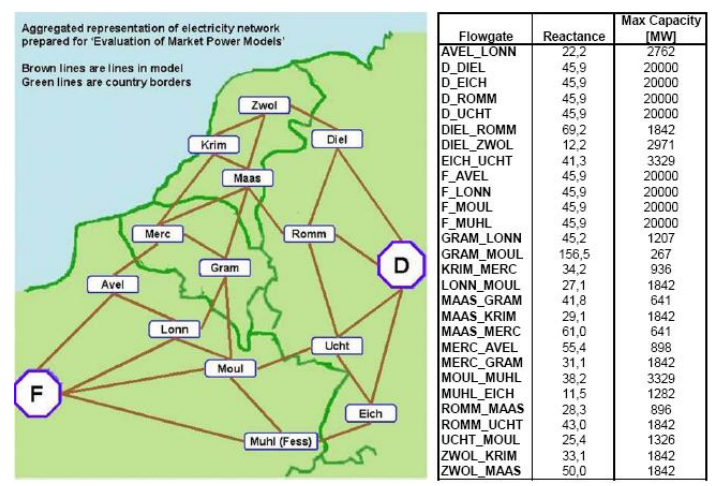

Figure 1: Northwestern European market and Network line capacities

We distinguish two consumer groups: households (representing small consumers of electricity and tertiary) and large industries with an intensive use of electricity. Their demand functions are assumed to be linear and differ over nodes. Moreover, it seems realistic to suppose a constant industrial consumption level over the year while small consumers demand more electricity in winter than in summer (see Table 13 in Appendix B). As already indicated, we limit ourselves to seasons assumed to respectively represent the peak and the off-peak periods. Demand curves are calibrated through a reference point and an elasticity at that point. A wholesale reference price of $40 € / \mathrm{MWh}$ is applied to small and industrial consumers' demand functions in both periods. Since our priority consists in analysing consumers' reactions to the introduction of the ETS, we model long-run demand function. Small consumers are expected to behave less flexible and then we assume that their demand elasticity is - 0.1 in the reference point. Contrarily, we set industrial consumers' demand elasticity at -1 in order to account for their ability to leave Europe in case of too high electricity prices ${ }^{6}$.

We adopt an emission cap $E$ of about 397 Mio ton p.a. We assume that the permit market is restricted to the power sector and we do not model permit trade among industries. The justification of this restriction is practical: there is no information available on the demand for allowance by large industrial consumers. We shall offer a formal extension of the current model that embeds the whole set of sectors covered by the EU-ETS. Given this restriction, the emission cap $E$ corresponds exactly to the sum of the NAPs of the electricity generating

\footnotetext{
${ }^{6}$ Since there is almost complete lack of information of demand response of industrial consumers, we took this -1 value from a slide of Newbery.
} 
companies included in the simulation tests. It defines the amount of emissions allowed in the power market. A detailed list of the allowance allocations per country and generating company is reported in Table 16 in Appendix B. Finally, market simulations are calibrated with data updated to 2005 (see Appendix B).

\section{Statement of the Reference Model}

The basic models simulate a perfectly competitive market with three main agents: power companies, consumers (households and industries) and the Transmission System Operator (TSO hereafter). All agents are supposed to be pricetakers and maximize their surpluses.

Power companies profit from selling electricity to both consumer groups. There is no price discrimination in perfectly competitive markets. Electricity price are thus identical in both market segments. Their generation activity is subject to a production balance and a technological constraint. The first ensures that the quantity of electricity produced is at least equal or greater than the amount sold. The second accounts for the limited production capacity of power plants.

Consumers maximize their surplus supposing that the amount of electricity demand is positive. Recall that, for the sake of realism, we assume that industrial consumption is constant over the year. To this aim, we add a constraint to the industrial optimization problem, imposing the equality of the hourly consumption of electricity during summer and winter.

The TSO maximizes the merchandising surplus accruing from transmission operations. As explained above, we include network constraints in PTDF form. The transmission market is thus a nodal system operating under perfect competition.

Last, we represent the allowance market through an emission balance equation and introduce a market clearing price for that market. The market clearing price on the allowance market is thus an output of the model. The perfectly competitive scenario including both the emission and the transmission constraints is our reference model. In Appendix A.1 we describe the mathematical formulation of this reference model. It is expressed in complementarity condition form.

\section{Results of the Reference Model}

In order to assess the long-run impacts of the EU-ETS on industries' electricity prices and demand, we compare the results of the reference model with and without emission constraint.

Our results are certainly in line with industries' claim: large industrial consumers decrease their electricity consumption by $-11 \%$ after the inception of the EU-ETS. This holds in both periods modelled ${ }^{7}$. This is accompanied by a cut of almost $-23 \%$ in their annual surplus. Table 1 shows industrial electricity hourly demand before and after the introduction of the emission constraint.

\footnotetext{
${ }^{7}$ This fall in their electricity consumption is significant, but it is really driven by our assumptions. The reader should indeed keep in mind that we model industries' long run behavior and hence assume a demand elasticity of -1 . This model assumption is selected to fit the threat, exposed by large consumers, of relocating their production capacities.
} 


\begin{tabular}{|l|r|r|r|}
\hline MW & Without ETS & With ETS & Relative Changes \\
\hline \hline Germany & 32,214 & 25,095 & $-22 \%$ \\
\hline France & 25,015 & 24,910 & $-0.4 \%$ \\
\hline Merchtem & 3,573 & 3,538 & $-1 \%$ \\
\hline Gramme & 2,029 & 1,963 & $-3 \%$ \\
\hline Krimpen & 2,722 & 2,603 & $-4 \%$ \\
\hline Maastricht & 942 & 889 & $-6 \%$ \\
\hline Zwolle & 1,800 & 1,615 & $-10 \%$ \\
\hline Total & $\mathbf{6 8 , 2 9 4}$ & $\mathbf{6 0 , 6 1 3}$ & $\mathbf{- 1 1 \%}$ \\
\hline
\end{tabular}

Table 1: Industry's hourly demand without and with EU-ETS

The inception of $\mathrm{CO}_{2}$ restrictive policies also introduces some contrasts in the inter-temporal electricity prices. They are respectively reported in Tables 2 and 3 and are identical for industries and households.

Transmission costs influence off-peak power prices. In fact, some of the grid connections are congested. In particular, lines are satured between France and Germany and between France and Belgium. The interconnection capacity between the Belgian node Merchtem and the Dutch node Krimpen is congested and the same happens between Gramme and Maastricht. The direction of the flows reveals that France exports both to Germany and Belgium, which, in turn, supplies the Netherlands. Since a great part of the nuclear electricity generated in France is exported, the congestion of the lines, combined with the marginal cost pricing implicit in this model, reduces the French power price to a level close to its marginal operating cost $(5.07 € / \mathrm{MWh})$. This happens even though the price of the neighboring countries is higher. The congestion cost makes the difference. In peak, instead, all consumers pay the price set

\begin{tabular}{|l|r|r|r|}
\hline \multicolumn{4}{|c|}{ SUMMER } \\
\hline \hline$€ /$ MWh & Without ETS & With ETS & Relative Changes \\
\hline \hline Germany & 21.62 & 44.94 & $108 \%$ \\
\hline France & 4.50 & 5.07 & $13 \%$ \\
\hline Merchtem & 36.35 & 46.91 & $29 \%$ \\
\hline Gramme & 19.09 & 27.79 & $46 \%$ \\
\hline Krimpen & 36.35 & 46.91 & $29 \%$ \\
\hline Maastricht & 36.35 & 46.91 & $29 \%$ \\
\hline Zwolle & 32.15 & 46.07 & $43 \%$ \\
\hline
\end{tabular}

Table 2: Off-peak electricity prices of industry and households in $€ / M W h$ without and with ETS

at the hub node because the transmission grid is no longer congested. This is only true in the carbon unconstrained version of the model. In fact, without carbon restriction, a line connecting France with Belgium is congested in peak period and, then, the standard economy of nodal transmission system makes electricity prices different in all nodes. Under the EU-ETS, consumers globally reduce their electricity demand and the amount of power exported in winter decreases, avoiding the congestion of the grid. It is then important to recognize the real nature of the phenomenon. The EU-ETS decreases congestion because it reduces industrial demand. 
The comparison reported in Table 2 shows that, with the EU-ETS, electricity prices increase in off-peak. The merit order of the plants can explain these seemingly strange results. We recall that, in perfect competition and when there are no transmission constraints, the most expensive plant defines electricity price at the hub node. With the implementation of the EU-ETS, generators are encouraged to exploit low emitting technologies, like CCGT, and reduce the utilization of more polluting ones (notably coal and lignite). In particular, hydro, "wind" and nuclear capacities are saturated in both periods; while CCGT plants are fully run in winter. In this case, CCGT technologies, together with the pass through of the allowance price, set the summer electricity price at a higher level than coal based plants would have done without the EUETS.

In peak, we observe a reverse behavior: under the emission trading policy, energy prices become lower. The combination of the change of plant merit order and the electricity demand cuts explains this outcome. The EU-ETS obliges generators to modify their fuel mix and to switch lower emitting plants in order to achieve their emission target. For all these reasons, CCGT power units determine the winter electricity price $(47.36 € / \mathrm{MWh})$, replacing the natural gas and oil based installations used in the case with no environmental regulation. This makes power cheaper than before. The requirement that industrial demand remains constant throughout explains how demand and price can simultaneously decrease. This is confirmed by the behavior of small consumers in the peak period: in presence of emission limitations, they increase by $1 \%$ their electricity consumptions, since prices are a little bit lower in each node. In off-peak, instead, they lessen their energy utilization (almost -3\%) as a consequence of the raised power prices. Table 3 reports the associated price relative changes.

\begin{tabular}{|l|r|r|r|}
\hline \multicolumn{4}{|c|}{ WINTER } \\
\hline \hline$€ /$ MWh & Without ETS & With ETS & Relative Changes \\
\hline \hline Germany & 51.48 & 47.36 & $-8 \%$ \\
\hline France & 47.48 & 47.36 & $-0.3 \%$ \\
\hline Merchtem & 57.26 & 47.36 & $-17 \%$ \\
\hline Gramme & 53.22 & 47.36 & $-11 \%$ \\
\hline Krimpen & 54.92 & 47.36 & $-14 \%$ \\
\hline Maastricht & 54.03 & 47.36 & $-12 \%$ \\
\hline Zwolle & 53.66 & 47.36 & $-12 \%$ \\
\hline
\end{tabular}

Table 3: Peak electricity prices of industry and households in $€ / M W h$ without and with ETS

The EU-ETS has thus two effects: first, it adds a carbon component to summer prices; second, it removes expensive and inefficient units in winter. These two effects interact with the constant (endogenous) demand level in the industrial sectors.

Under the EU-ETS restrictions, the allowance price found is $24.44 €$ /ton. This positive value signals a tight emission cap. This contradicts the low allowance price that prevailed in the second part of the first compliance period after global NAPs were commonly judged excessive. Our figures can easily be confirmed through the common wisdom about the total NAPs in the first compliance period. Reinaud (see [12]) and Smeers (see [18]) explain that CCGT 
and coal plants become competitive when $\mathrm{CO}_{2}$ price reaches a certain "tapping point". In particular, Smeers in [18] argues that this shift between CCGT and coal happens for $\mathrm{CO}_{2}$ price of around $23.65 € /$ ton. Reinaud in [12] indicates a $\mathrm{CO}_{2}$ cost of $19 € /$ ton. Our results are aligned with these studies: only with a high permit price (like $24.44 €$ /ton), one forces electricity generating companies to replace coal technology with less emitting CCGT stations. This is exactly what we have observed ${ }^{8}$.

With the application of the environmental policy, carbon emissions globally reduce by $-14 \%$ from a level of about 464 Mio ton p.a. to 397 annual Mio ton. This is exactly the $\mathrm{CO}_{2}$ emission ceiling imposed on the power sector in the model. Parallel to the global reduction in electricity consumption, one observes a decreasing emission level in almost all the nodes of the model. There are two exceptions through: they occur in the Dutch locations Maastricht and Zwolle. In the first of these two nodes, the global pollution level increases with respect to the unconstrained carbon case. Power producers, in fact, raise the operation of their CCGT plants in order to reduce their electricity imports, as a consequence of the congestion of the line between Maastricth and the Belgian node Gramme. In Zwolle, instead, the emissions remain constant, since both the capacity and the fuel mix used to produce energy do not change with respect to the unconstrained carbon case.

Finally, under these conditions, electricity generating companies' profit globally increases by $16 \%$ with respect to the unconstrained carbon case. All these comply with industrial position: there might be a problem of competitiveness and demand destruction. This justifies to explore their solution proposal.

\section{$5 \quad$ Average Cost Pricing Mechanism}

Our results comply with the thesis that the implementation of the EU-ETS increases electricity prices and induce a corresponding reduction of consumers' demand, at least in the long run. This effect is not really surprising and results from basic economic phenomenons. Carbon leakage indeed implies both increase of emissions and loss of economic activity. The phenomenon serves neither the EU nor the environment. In order to explore a possible alternative to that outcome, we modify the basic model and assume that industrial consumers either pay full average generation cost or directly control part of the generating capacity installed in the network.

This approach has two implications: the market is segmented into two submarkets respectively representing the electricity intensive industries and households. As a direct consequence, the generation system is also split between these two market segments. This subdivision is endogenously determined since

\footnotetext{
${ }^{8}$ Smeers and Reinaud indicate different $\mathrm{CO}_{2}$ switching price. This because their studies are based on different input data. Reinaud assumes that coal and gas fuel prices are respectively $1.5 € /$ GJ and $3.5 € / G J$; while those of Smeers' study are higher: $2.3 € /$ GJ (coal) and 3.5 $€ /$ GJ (gas). Efficiency rates are identical $(0.37$ (coal) and 0.49 (gas)) and also gas emission factor (0.412 ton/MWh). Smeers supposes that coal emits more than Reinaud does (0.99 ton/MWh vs 0.918 ton/MWh). In order to check the consistency of these two studies, we compute the $\mathrm{CO}_{2}$ switching price using Smeers' formula and Reinaud's input data. The result obtained is $19.24 € /$ ton that is aligned with Renaiud's value. Our input data are more similar to those adopted by Smeers. In particular, we assume that coal costs $2.22 € /$ GJ with an emission rate of 0.9542 and efficiency rate of 0.37 ; while gas price is $4.15 € / \mathrm{GJ}$ with an emission factor of 0.432 and efficiency rate of 0.49 . For more details, see Table 15 and [1].
} 
the final demand of the large industrial consumers is also endogenously determined. We shall see that the principle underlying this allocation is to equalize the marginal value of the capacities allocated to the two segments. This also implicitly amounts to maximizing the total capacity value. Within this market segmentation, we assume that small consumers are still priced at the short-run marginal costs. In contrast, electricity intensive industrial consumers pay electricity at the average costs corresponding to the full cost of the power plants reserved for them. We consider two particular applications of this view.

We first represent a case where industrial consumers can purchase electricity at the same average cost price in any node by the means of a power purchase consortium. The assumption corresponds to a request of the large consumers to achieve a single price on the continental "copper plate" through extended countertrading. Large industrial consumers (and also seemingly the European Consumers) indeed see it desirable, bearing sufficient investment in transmission, to develop countertrading and to a single electricity price in regional market. In this scenario, the final electricity price they faced by large industrial consumers would include both the average production and the average transmission costs, which consumers generally pay to the TSO.

We also model a second case, where we suppose that industrial consumers buy only the electricity produced in the node where they are located. This leads to a nodal average cost based price system. In this way, industrial consumers are relieved of paying transmission costs, but they are subject to the various constraints that affect generation at that node. In other words, they are not free to choose the technology used to supply them. This makes electricity prices strictly depending on the fuel mix at the node. Subsection 5.1 describes the results of the average cost models.

The average cost price formulation makes the mathematical problem more complex because averaging processes destroy the monotonicity properties of the model. Average cost pricing may also make the problem infeasible. This will be in particular the case if the fixed charge allocated to the price increases this latter too much. In order to attempt to mitigate numerical difficulties, we solve the average cost based models as a sequence of two different sub-problems. For each average cost price models, we first simulate a market with capacity splitting and demand segmentation where both consumer segments are priced at the same short-run marginal costs (the so-called "preliminary problem"). This always has a solution. This preliminary step amounts to simulating a standard competitive model. Its solution is employed as starting point for solving the problems with average cost pricing system.

We then run the average cost pricing models. These problems may not have a solution ${ }^{9}$. The surplus maximization problem representing the small consumers is identical in both the preliminary and the average cost problems; changes concern only industrial consumers' equations. For the sake of simplicity, we do not report the formulation of the preliminary models. The reader should simply note that these preliminary models are quite similar to the average cost problems presented in the following sections: one just replaces the average cost with a marginal cost based price.

\footnotetext{
${ }^{9}$ In our specific cases, we can find solution to the single and the nodal average cost pricing scenarios both with or without the preliminary model. Nevertheless, these two approaches give different results. As indicated, this is perfectly possible in theory because of non monotonicity; it also occurs in practice.
} 
Both average cost pricing mechanisms adopt the same representation of perfectly competitive transmission and emission markets as the reference model. Moreover, the main structure and the constraints of the average cost based problems are quite similar to the those of the reference case. Power producers desire to maximize their annual profits under the standard production and capacity constraints. On the other side, consumers maximize their global surpluses. The complementarity conditions of the single and the nodal average cost pricing systems are presented respectively in Appendices A.2 and A.3.

\subsection{Results of the Average Cost Pricing Models}

Our analysis shows that single and nodal average cost based contracts have different impacts on industries. These depend on their location and the technological mix used to produce electricity in each node. Tables 4 and 6 report their values. The single average cost price amounts to $38.10 € /$ MWh. Fixed costs contribute for the largest part, followed by the fuel and the emission charges. Industries tend to congest the network and for this reason they pay transmission costs to the TSO.

The application of the single average cost pricing system results in a global increase of $+5 \%$ of the industrial electricity consumption with respect to the reference case. This is the desired objective of the policy. However, not all industrial consumers benefit from the application of this innovative pricing scheme. In Germany, in the Netherlands and in the Belgian location Merchtem industries pay electricity at lower prices. Relative changes are between -19\% (in Merchtem, Krimpen and Maastricht) and $-17 \%$ (in Germany). Instead, in France and in the Belgian node Gramme the comparison with the marginal cost case shows that a single average cost price leads to an increase of $+69 \%$ and $+6 \%$ respectively. The direct consequence is that industrial consumers require less electricity. The decreases of $-22 \%$ (in France) and $-1 \%$ (in Gramme) are compensated by the increase of industrial electricity demand in the other nodes. Table 5 reports in absolute values industries' hourly electricity demand under different pricing scenarios.

\begin{tabular}{|l|r|}
\hline Cost Components & $€ /$ MWh \\
\hline \hline Fuel & 10.64 \\
\hline Transmission & 2.74 \\
\hline Emission & 7.32 \\
\hline Capacity & 17.39 \\
\hline Average cost price & $\mathbf{3 8 . 1 0}$ \\
\hline
\end{tabular}

Table 4: Single average cost price

The endogenous allocation of the installed capacity may offer a plausible explanation to these results. A great part of the total base-load technologies (hydro (60\%), nuclear $(52 \%)$ and lignite $(62 \%)$ ) existing in the network is now reserved for industries. Also $71 \%$ of the available "wind" capacity is dedicated to industrial consumers. Both in France and in Gramme, electricity generating companies reserve only clean technologies (namely hydro, "wind" and nuclear) for industries. As expected, France plays an important role in this market segment, since it covers almost the entire industrial electricity demand that the 
bordering countries are not able to satisfy. In fact, the nuclear capacity that French generators reserved for the industry is larger than the amount they really need for their own (industrial) consumers and then anyone can have access to the exceeding part. This allows meeting the industrial market energy balance. This has an obvious side effect; this affects the French industries' competitive positions, which now have to buy electricity at a higher price. Moreover, because of the capacity split, French small consumers have a limited access to nuclear power. This has also a further negative consequence on their electricity prices, especially in winter, when their energy consumption is higher. In fact, during the peak period the capacity reserved for French small consumers is not sufficient to meet their entire demand and therefore they have to import more expensive electricity. One encounters a similar situation in Gramme, where local industries have to share their hydro, "wind" and nuclear plants with foreign large consumers.

With respect to the reference case, households face higher electricity prices both in peak and off-peak periods. This is partially due to the endogenous split in capacity that reserves cheap and base-load technologies to industrial consumers. In off-peak, CCGT plants set electricity prices after accounting for the corresponding carbon cost. In peak, instead, natural gas and oil based installations become again active and determine the prices. Moreover, in this case, permits are more expensive $(+17 \%)$ than in the reference scenario. In fact, power companies have to produce more electricity to fully cover industrial requests. Although small consumers face electricity price increases, their global demand does not vary too much with respect to the reference case ${ }^{10}$. The industrial demand effect prevails over household consumption. This results in a growth of the amount of electricity produced and, consequently, of the demand for allowances. Since carbon emissions are capped, the allowance price increases ${ }^{11}$.

\begin{tabular}{|l|r|r|r|}
\hline MW & Reference case & Single Average case & Nodal Average case \\
\hline \hline Germany & 25,095 & 31,065 & 26,913 \\
\hline France & 24,910 & 19,408 & 29,002 \\
\hline Merchtem & 3,538 & 4,511 & 2,176 \\
\hline Gramme & 1,963 & 1,939 & 2,601 \\
\hline Krimpen & 2,603 & 3,319 & 2,119 \\
\hline Maastricht & 889 & 1,133 & 620 \\
\hline Zwolle & 1,615 & 2,033 & 1,113 \\
\hline Total & $\mathbf{6 0 , 6 1 3}$ & $\mathbf{6 3 , 4 0 8}$ & $\mathbf{6 4 , 5 4 3}$ \\
\hline
\end{tabular}

Table 5: Comparison of the industrial consumers' hourly demand under different pricing scenarios

The application of the nodal average cost based policy has a global positive effect on industries: they increase their electricity consumption with respect to both the reference $(+6 \%)$ and the single average cost price $(2 \%)$. Looking at the hourly demand values reported in Table 5 , one can easily notice that industrial consumers assume different positions in relation to the node where they are

\footnotetext{
${ }^{10}$ Totally small consumers reduce their demand by $-0.4 \%$ in off-peak and by $-2.8 \%$ in peak We recall that we assume that they have a small price elasticity.

${ }^{11} \mathrm{With}$ respect to the reference case, allowance price augments by $+17 \%$. In fact, it reaches a cost of $28.48 € /$ ton starting from a value of $24.44 € /$ ton.
} 
located. In France and in the Belgian node Gramme, the nodal average cost pricing system represents the best policy to heal industrial difficulties. This is mainly a result of the technological structure in these locations. In a country, like France, where nuclear is the main power source, nodal average cost pricing contracts perfectly suit industrial consumers' needs, since they have wide access to this cheap and clean technology without sharing it with foreign consumers ${ }^{12}$. On the other side, the situation of industries placed in nodes where electricity is mostly produced by CCGT or coal based technologies is more critical. This is what happens in the Netherlands and in the Belgian node Merchtem, where industries are really damaged by this new contractual policy ${ }^{13}$. In Germany, instead, the industrial electricity consumption decreases by $-13 \%$ with respect to the single average cost case, but it is higher in comparison to the reference level $(+7 \%)$.

\begin{tabular}{|l|r|r|r|r|}
\hline$€ /$ MWh & Fuel & Emission & Capacity & Average cost price \\
\hline \hline Germany & 11.59 & 17.59 & 14.52 & $\mathbf{4 3 . 7 0}$ \\
\hline France & 4.50 & 0.00 & 12.89 & $\mathbf{1 7 . 3 9}$ \\
\hline Merchtem & 25.76 & 22.77 & 11.25 & $\mathbf{5 9 . 7 9}$ \\
\hline Gramme & 9.03 & 1.75 & 13.01 & $\mathbf{2 3 . 7 9}$ \\
\hline Krimpen & 25.58 & 15.56 & 12.11 & $\mathbf{5 3 . 2 5}$ \\
\hline Maastricht & 36.35 & 12.19 & 8.53 & $\mathbf{5 7 . 0 6}$ \\
\hline Zwolle & 36.35 & 12.19 & 8.53 & $\mathbf{5 7 . 0 6}$ \\
\hline
\end{tabular}

Table 6: Nodal average cost price

The contribution of the three components of the nodal average prices (fuel, emission and fixed costs) shown in Table 6 may explain these results. They depend on the nodal technology mix. For instance, in France, the industrial electricity price is $17.39 € / \mathrm{MWh}$, of which $4.50 € / \mathrm{MWh}$ are the average fuel costs and $12.89 € / \mathrm{MWh}$ are the fixed charges. Electricity producers exploit only nuclear plants ${ }^{14}$ to cover French industrial demand. Nuclear is an environmentalfriendly technology and then French average cost based price does not include emission burdens. Fuel and capacity charges correspond exactly to the costs of a nuclear plants, as indicated in Tables 15 and 17 in Appendix B. In Gramme, industries are mainly supplied by hydro, "wind" and nuclear. Moreover, $31 \%$ and $100 \%$ of the available CCGT and natural gas plants are employed, but these proportions correspond to a few MW of capacity (respectively $373 \mathrm{MW}$ and $170 \mathrm{MW}$ ). Hydro and "wind" reduce the fuel average cost; while emissions caused by CCGT and natural gas stations add to this cost. Contrarily, industrial consumers in Merchtem, the other Belgian node, face the highest nodal average cost price of the market. Electricity generating companies, in fact, use the entire amount of coal capacity (1,564 MW) and 24\% (612 MW) of the CCGT plants installed in the node to cover their electricity demand. All the clean power stations (namely hydro, "wind" and nuclear) are dedicated to households. As indicated in Table 6, this implies high emission costs. Dutch industries in Maastricht and in Zwolle are only supplied by CCGT stations; in Krimpen, instead,

\footnotetext{
${ }^{12}$ It is exactly the opposite of what happens in the single average cost pricing scenario.

${ }^{13}$ Their electricity cuts are as follows: $-39 \%$ (reference case) and $-52 \%$ (single average) in Merchtem, $-19 \%$ (reference case) and $-36 \%$ (single average) in Krimpen, $-30 \%$ (reference case) and $-45 \%$ in Maastricht and, finally, - 31\% (reference case) and -45\% (single average) in Zwolle.

${ }^{14}$ Precisely $64 \%$ of the nuclear capacity installed corresponding to $29,002 \mathrm{MW}$.
} 
the set of the technologies given to industries is composed of "wind", nuclear, coal and CCGT.

Finally, German industries are mostly supplied by lignite technologies, accompanied by nuclear, lignite, hydro and "wind": this is the reason why emission charges have the major weight in their prices.

\begin{tabular}{|l|r|r|r|r|r|}
\hline GWh & \multicolumn{3}{|c|}{ Households } & Industry & Total \\
\hline \hline & Summer & Winter & Total & & \\
\hline \hline Reference case & 244 & 402 & $\mathbf{6 4 6}$ & 530 & $\mathbf{1 , 1 7 6}$ \\
\hline Single Average case & 243 & 391 & $\mathbf{6 3 4}$ & 555 & $\mathbf{1 , 1 8 9}$ \\
\hline Nodal Average case & 231 & 392 & $\mathbf{6 2 3}$ & 565 & $\mathbf{1 , 1 8 8}$ \\
\hline
\end{tabular}

Table 7: Consumers' annual demand under different pricing scenarios

The comparison of the nodal average cost case with the reference model shows that the application of this average cost pricing mechanism has a global negative influence on households. We recall that, in a transmission constraint free system, small consumers' prices are determined by the last power station used to produce electricity augmented by the associated carbon cost. Since, both in the reference and in the nodal average cost models, CCGT plants are the margin; differences of electricity prices depend only on carbon cost. In fact, in the reference case, allowances are cheaper than in the nodal average cost case $(24.44 € /$ ton vs $28.21 € /$ ton $)$.

On the other side, the analysis of the two average cases highlights that small consumers' demand assumes different trends in relation to the node and the period considered: apart in Merchtem, they globally reduce their electricity consumption in off-peak (-4.76\%); while in peak only French households lessen their electricity consumption (-3.3\%). These results are still affected both by the permit price (that in this case is $28.21 € /$ ton) and the fuel mix.

\begin{tabular}{|l|r|r|r|r|}
\hline Billion $€$ & Ref. NO EU-ETS & Ref. EU-ETS & \multicolumn{1}{c|}{ Single A. } & \multicolumn{1}{c|}{ Nodal A. } \\
\hline \hline Benefit & & & & \\
\hline \hline Industry & 13.803 & 11.201 & 11.637 & 13.488 \\
\hline Households & 130.869 & 129.354 & 124.648 & 120.202 \\
\hline Consumers & $\mathbf{1 4 4 . 6 7 2}$ & $\mathbf{1 4 0 . 5 5 5}$ & $\mathbf{1 3 6 . 2 8 5}$ & $\mathbf{1 3 3 . 6 9 0}$ \\
\hline & & & & \\
\hline Generators & $\mathbf{2 5 . 2 2 3}$ & $\mathbf{1 9 . 5 3 4}$ & $\mathbf{2 1 . 6 2 7}$ & $\mathbf{2 5 . 5 7 5}$ \\
\hline & & $(29.246)^{\mathrm{a}}$ & $(32.943)^{\mathrm{a}}$ & $(36.785)^{\mathrm{a}}$ \\
\hline & & & & \\
\hline TSO & $\mathbf{0 . 6 4 7}$ & $\mathbf{0 . 9 0 2}$ & $\mathbf{1 . 2 6 5}$ & $\mathbf{0 . 1 0 1}$ \\
\hline & & & & \\
\hline Welfare & $\mathbf{1 7 0 . 5 4 2}$ & $\mathbf{1 6 0 . 9 9 1}$ & $\mathbf{1 5 9 . 1 7 7}$ & $\mathbf{1 5 9 . 3 6 6}$ \\
\hline
\end{tabular}

Table 8: Welfare analysis under different pricing scenarios

${ }^{a}$ Generators' profits accounting for the value of the carbon permits received for free.

Table 7 compares consumers' annual demand under the pricing scenario considered. The results therein reported confirm the tendency described.

The application of the average cost pricing systems induces a welfare redistribution among market players. This is shown in Table 8. Small consumers 
maximize their surplus under a perfectly competitive market. On the other side, industries benefit a lot from buying electricity at the nodal average cost price. Their surplus increases by $+20 \%$ and $+16 \%$ compared to the reference and the single average cost case respectively. With the inception of the EU-ETS and without free allowances, that is if allowances are auctioned, generators' profits become lower ${ }^{15}$. This is due the fact that, power companies have now to account for the additional burdens caused by emissions. This holds in all cases except for the nodal average cost scenario where power producers increase their profit by $+1 \%$ with respect to the model without EU-ETS regulation. This extra gains come from selling electricity to households. Recall that this welfare analysis does not include the value of the $\mathrm{CO}_{2}$ permits that electricity producers would still receive for free. However, in Table 8, we report also the case when free allowances are included in the computation of generators' profits. Note that, under this assumption, generators' benefits are much higher. These results support the theory of the so-called windfall profits (see [14]). Finally, the TSO's merchandising surplus depends on network utilization. For instance, in the reference case with carbon restriction, the TSO only makes profit in summer, when the network is congested. In contrast, the construction of the nodal average cost case implies that the TSO only receives payments from households. Moreover, these payments are very low with respect to the other cases because only one line, connecting Germany to France, is congested and this occurs only in winter. One can note that one falls back on the standard result of economic theory that perfect competition maximizes global welfare.

\section{Sensitivity and Robustness Analysis}

In this Section, we conduct a sensitivity analysis in order to check how industrial consumers' demand and emissions vary when one modifies the assumptions regulating the permit market. In our models, we endogenously determine carbon price and explore its modification under different electricity pricing mechanisms. We now simplify our models by directly introducing an exogenous permit price. We test two cases when:

1. Permit price is set at $10 € /$ ton (hereafter "EU-ETS PP 10" case)

2. Permit price is set at $20 € /$ ton (hereafter "EU-ETS PP 20" case)

and we compare the results with those of the original version of our models. This test requires a small modification of the model. An exogenous allowance price dispenses with the need to explicitly model the market of allowances. This implies that there is no need to retain the emission constraint in the model. Power companies buy and sell permits on the market at exogenously given prices. In contrast with we have done before, we first define a permit price and then we compute the amount of emissions generated. Note that the endogenous permit prices found in the previous sections are higher than those tested here. Obviously, the lower carbon charges are and the higher $\mathrm{CO}_{2}$ emitted will be.

\footnotetext{
${ }^{15}$ The comparison among the perfect competition model without carbon constraint and the other scenarios results in the following profit cuts: $-23 \%$ (reference case with EU-ETS) and $-14 \%$ (single average cost case).
} 
Recall that the reference model without emission restrictions, industries globally consume $68,294 \mathrm{MW}$ of electricity per hour. This amount decreases and falls to $60,613 \mathrm{MW}$ when we set a cap of 397 ton p.a. The endogenous value of the associated permit price is $24.44 € /$ ton. Instead, when we fix a price of 10 $€ /$ ton, industrial consumption increases by $+4 \%$ with respect to the reference case with EU-ETS regulation, because electricity becomes cheaper ${ }^{16}$. Also small consumers' demand raises.

As indicated in Table 9, annual emissions are about 419 Mio ton $(+6 \%$ with respect to the reference case). This is due to the fact that electricity generating companies exploit more lignite/coal and CCGT plants in order to cover the increased wholesale demand. With such a low permit price, lignite/coal stations remain more competitive than CCGT stations. A similar reasoning holds when we apply a permit price of $20 € /$ ton. Industries demand $61,946 \mathrm{MW}$ of electricity each hour. In this case, the increase with respect to reference endogenous case is $3 \%$, lower than in the "EU-ETS PP 10" scenario. Imposing a permit price of $20 € /$ ton makes electricity more expensive. Under this assumptions, the global amount of $\mathrm{CO}_{2}$ emitted is 407 Mio ton (see Table 9).

A similar reasoning can be applied to the sensitivity analysis conducted on the single average cost pricing models. Fixing the permit price at $10 € /$ ton entails a huge increase $(+10 \%)$ of the industrial consumers' electricity consumption. In fact, starting from a hourly consumption of $63,408 \mathrm{MW}$, when the carbon price is endogenous, industries now demand 69,723 MW. This depends on the fact that the single average cost price is set at $33.92 € / \mathrm{MWh}$, that is, $11 \%$ less than the single average cost price of the original model $(38.10 € / \mathrm{MWh})$. Imposing a permit price of $20 € /$ ton has still a positive impact on industries, even if the raise in their global electricity consumption is only $+3 \%$. We recall that in the original version of this model, $\mathrm{CO}_{2}$ permits cost $28.48 € /$ ton. The more lenient emission prices in combination with increased electricity demand explain why emission levels now reach the high level of 464 Mio ton and 441 Mio ton respectively in the "EU-ETS PP 10" and "EU-ETS PP 20" scenarios (see Table 9). Note that 464 Mio ton corresponds exactly to the pollution level without any environmental regulation.

The application of a mild environmental policy, like "EU-ETS PP 10" also induces industries to consume a lot of power in the nodal average cost model. The consumption increase with respect to the original version of the model is about $11 \%(71,840 \mathrm{MW})$. In the "EU-ETS PP 20", the global electricity consumption only increases by $+3 \%(66,619 \mathrm{MW})$. Again, this implies higher $\mathrm{CO}_{2}$ emissions as indicated in Table 9. In particular, when the permit price is fixed at $10 € /$ ton, global emissions amount to 471 Mio ton, that is even higher than the total carbon emitted in absence of an environmental regulation. This suggests that the Regulator should impose a restrictive cap to emissions in order to achieve the EU-ETS goal and make clean technologies more competitive.

We further check the robustness of our results by analysing the case when industrial consumers' demand is less elastic. Starting from the same reference demand point (see Section 2 ), we set the elasticity at that point at -0.8 instead of -1. This obviously modifies the results (for all agents included in the models), but keeps consumption and price trends almost identical. Tables 10 reports annual consumers' demand. As in Table 7, industries increase their electricity

\footnotetext{
${ }^{16}$ This is due the fact that the $\mathrm{CO}_{2}$ contribution to the power price is reduced.
} 


\begin{tabular}{|l|r|r|r|r|}
\hline Mio ton & & PP endogenous & PP 10 & PP 20 \\
\hline \hline Reference case before EU-ETS & 464 & & & \\
\hline Reference case after EU-ETS & & 397 & 419 & 407 \\
\hline Single Average case & & 397 & 464 & 441 \\
\hline Nodal Average case & & 397 & 471 & 423 \\
\hline
\end{tabular}

Table 9: Emission level under different pricing scenarios

consumption in the average cost pricing system. Again, the increment is higher with nodal average cost based contracts. Small consumers, instead, suffer from pricing discrimination and reduce their power demand. Nevertheless, this new industrial elasticity assumption modifies some results of the nodal average cost model.

\begin{tabular}{|l|r|r|r|r|r|}
\hline GWh & \multicolumn{3}{|c|}{ Households } & Industry & Total \\
\hline \hline & Summer & Winter & Total & & \\
\hline \hline Reference case & 243.3 & 402 & $\mathbf{6 4 5 . 3}$ & 524 & $\mathbf{1 , 1 6 9}$ \\
\hline Single Average case & 242.7 & 391 & $\mathbf{6 3 3 . 7}$ & 554 & $\mathbf{1 , 1 8 8}$ \\
\hline Nodal Average case & 239.9 & 396 & $\mathbf{6 3 5 . 9}$ & 556 & $\mathbf{1 , 1 9 2}$ \\
\hline
\end{tabular}

Table 10: Consumers' annual demand under different pricing scenarios. Industrial elasticity 0.8 .

\begin{tabular}{|l|r|r|r|r|}
\hline Billion $€$ & Ref. NO EU-ETS & Ref. EU-ETS & \multicolumn{1}{c|}{ Single A. } & \multicolumn{1}{c|}{ Nodal A. } \\
\hline \hline Benefit & & & & \\
\hline \hline Industry & 16.456 & 13.455 & 14.466 & 15.334 \\
\hline Households & 131.009 & 129.052 & 124.650 & 125.294 \\
\hline Consumers & $\mathbf{1 4 7 . 4 6 5}$ & $\mathbf{1 4 2 . 5 0 7}$ & $\mathbf{1 3 9 . 1 1 6}$ & $\mathbf{1 4 0 . 6 2 8}$ \\
\hline & & & & \\
\hline Generators & $\mathbf{2 4 . 9 9 2}$ & $\mathbf{1 9 . 3 8 1}$ & $\mathbf{2 1 . 4 5 7}$ & $\mathbf{2 1 . 1 6 2}$ \\
\hline & & $(29.791)^{\mathrm{a}}$ & $(32.770)^{\mathrm{a}}$ & $(32.463)^{\mathrm{a}}$ \\
\hline & & & & \\
\hline TSO & $\mathbf{0 . 6 5 4}$ & $\mathbf{0 . 9 4 2}$ & $\mathbf{1 . 2 6 4}$ & $\mathbf{0 . 7 7 9}$ \\
\hline & & & & \\
\hline Welfare & $\mathbf{1 7 3 . 1 1 1}$ & $\mathbf{1 6 2 . 8 3 0}$ & $\mathbf{1 6 1 . 8 3 7}$ & $\mathbf{1 6 2 . 5 6 9}$ \\
\hline
\end{tabular}

Table 11: Welfare analysis under different pricing scenarios. Industrial elasticity -0.8 .

a Generators' profits accounting for the value of the carbon permits received for free.

In particular, households' electricity demand is higher than in the single average cost pricing case. In the original version of the model (industrial elasticity set at -1), one faces the reverse situation. The comparison among the results reported in Tables 10 and 7 shows that industrial electricity demand is reduced. Consequently, they need less capacity that now becomes available for small consumers. Households therefore increase their electricity consumption in both periods. This raises network congestion and allows TSO to increase its merchandising surplus as indicated in Table 11, where we report the results 
of the welfare analysis conducted under the industrial elasticity assumption of -0.8 .

\section{Conclusion}

The special contracts tested in this paper represent one response proposal of European industrial consumers to the new environment created by the EU-ETS. It implies changing the pricing system to mitigate the increase of electricity prices caused by the EU-ETS. We test two different average cost pricing policies (single and nodal ones) that have different effects on industries.

A common point, discussed in Section 5, is that average cost based pricing encourages industries to maintain their activities (here represented by consumption of electricity) with respect to the reference level at least under the condition retained in this model (exogenous capacities and efficient transmission market). However, neither the single nor the nodal average cost pricing mechanisms completely mitigate the burdens imposed by the EU-ETS on the industrial sector. The first policy negatively affects French and part of the Belgian electricity intensive users, who, instead, profit of the second average strategy. In Germany, in Merchtem and in all Dutch nodes, industries face the opposite situation. The conclusion is that the impact of these special contracts on electricity intensive consumers depends on the particular pricing scheme implemented (single or nodal) and on the fuel mix adopted to produce electricity in the countries where industries operate. This is obviously the key factor, which defines power average cost based prices.

Finally, the high emission allowance price reveals the stress that the generation system is currently subject to. This suggests that investments in renewable power technologies, the improvement of the efficiency of the existing electricity units and the replacing of old power units are very needed. But looking at this problem requires capacity expansion model.

\section{References}

[1] K. Davis and URS Corporation, Greenhouse Gas Emission Factor Review, Edison Mission Energy, 2003.

[2] D. Demailly and P. Quirion, $\mathrm{CO}_{2}$ abatement, competitiveness and leakage in the European cement industry under the EU-ETS: grandfathering versus output-based allocation, Climate Policy, 6(2006), pp. 93-113.

[3] S.P. Dirkse and M.C. Ferris, The PATH solver: a nonmomotone stabilization scheme for mixed complementarity problems, Optm. Methods Software, 5(1995), pp. 123-156.

[4] ECN, Evaluation of models for market power in electricity networks Test data, Retrieved December 2003. Available at http : //www.ecn.nl/en/ps/products - services/models - and instruments/competes/model - evaluation/. 
[5] European Commission, National Reports on Verified Emission and Surrendered Allowances, Retrieved April 2006. Available at

http ://ec.europa.eu/environment/climat/emission/reviewen.htm.

[6] Eurostat, Consumption of electricity by industry, transport activities and households/services, Retrieved June 2006.

Available at $h t t p: / /$ epp.eurostat.ec.europa.eu.

[7] F. Facchinei and J. S. Pang, Finite-Dimensional Variational Inequalities and Complementarity Problems, Springer, Volume I, 2002.

[8] IEA, Projected Costs of Generating Electricity. International Energy Agency, 2005.

[9] McKinsey and Ecofys, EU ETS Review, Report on International Competitiveness, European Commission, DG Environment, 2006.

[10] A. Nagurney, Network Economics, A Variational Inequalities Approach, Klumer Academic Publishers, 1993.

[11] U. Oberndorfer and K. Reggings, The Impacts of the European Union Emissions Trading Scheme on the Competitiveness in Europe, Discussion Paper No. 06-051, ZEW Centre for European Economic Research, 2006.

[12] J. Reinaud, Emission Trading and Its Possible Impacts on Investment Decisions in the Power Sector, IEA Information Paper, 2003.

[13] - Industrial Competitiveness under the European Union Emission Trading Scheme, IEA Information Paper, 2005.

[14] J.P.M. Sijm, K. Neuhoff and Y. Chen, Cost Pass Thought and Windfall Profits in the Power Sector, Climate Policy 5 (2006), pp. 61-78.

[18] Y. Smeers, Assessment of EU $\mathrm{CO}_{2}$ Regulation, Ifri Energy Roundtable, January 30, 2007.

[15] UCTE, National electricity consumption 2005 and peak load, Retrieved May 2006. Available at http ://www.ucte.org/services/onlinedatabase/consumption/.

[16] UCTE, Monthly Consumption of a specific country for a specific range of time, Retrieved May 2006. Available at http : //www.ucte.org/services/onlinedatabase/consumption/.

\section{Appendix A. Complementarity Problem}

The models used in this study are all formulated as complementarity problems. First, we briefly present the mathematical formulation of the complementarity problems (CPs) and, then, we describe the models implemented (see $[7,10]$ for a presentation of complementarity problems). From a mathematical point of view, CPs are defined as follows: 
Definition 1 Let $R_{+}^{n}$ denote the nonnegative orthant in $R^{n}$. Given a mapping $F: R_{+}^{n} \rightarrow R^{n}$, the $M C P$ is to find a vector $x^{*} \in R^{n}$ such that:

$$
0 \leq x^{*} \perp F\left(x^{*}\right) \geq 0
$$

The use of the term "complementarity" to indicate these conditions derives directly from the concept of orthogonality $(\perp)$ stated by definition. In other words, solving a MCP consists in finding $x^{*} \geq 0$ such that:

$$
F\left(x^{*}\right) \geq 0 \quad \text { and } \quad F\left(x^{*}\right) x^{*}=0
$$

Condition (1) is the compact form we adopt for the CPs formulation of our models. These CP problems are implemented in the GAMS modelling environment adopting PATH as solver (see [3]).

Complementarity-based models offer a natural approach to construct equilibrium model. A market comprises different agents that produce, trade and consume different commodities. Standard microeconomic theory suggests to represent each agent by an optimization problem (profit or surplus maximization). Complementarity models readily derive from this principle. Complementaritybased formulations are created by first writing the first-order conditions (KKTs) of the maximization problems of the agents included in the models studied ${ }^{17}$ and, then, adding market equilibrium conditions ${ }^{18}$. The CPs system obtained should be square: one should have as many variables as complementarity conditions. It implies a correspondence one to one between variables and complementarity conditions.

\section{Appendix A.1. Reference case with emission and transmis- sion constraints}

The reference model describes a perfectly competitive energy market complemented by equally perfectly competitive nodal transmission and allowance markets. There is no market discrimination in perfect competition and then households and industries pay identical electricity prices. These are determined by the short-run marginal cost of the last running plant. The construction of the model is based on the following principle.

Electricity generating companies maximize their profits accounting for the production balance and the technological constraint. The complementarity version of their model is stated by equilibrium conditions (3-6) and can be interpreted as follows. Let $p_{i}^{t}$ be the electricity price at node $i$ and period $t$ and $\eta_{f, i}^{t}$ the short-run marginal production costs faced by power firm $f$ in node $i$ and period $t$. Condition (3) defines the equality between these two variables for positive level of electricity $g_{f, i}^{t}$ sold by firm $f$ in node $i$ in period $t$. Let $\lambda$ be the allowance price and $\nu_{f, i, m}^{t}$ the scarcity rent of a plant running at maximal capacity. As indicated in (4), $\eta_{f, i}^{t}$ accounts for the plant fuel costs $\operatorname{cost}_{f, i, m}$, the emission opportunity cost $\mathrm{em}_{m} \cdot \lambda$ and the $\nu_{f, i, m}^{t}$ scarcity rent. Note that $\mathrm{em}_{m}$ indicates the emission factor of technology $m$ and the permit price $\lambda$ is paired to the emission constraint (15) to express the market clearing of allowances.

\footnotetext{
${ }^{17}$ In our case, electricity generating companies and consumers.

${ }^{18}$ Emission and transmission constraints and equilibrium on energy, emission and transmission markets.
} 
Firm $f$ produces $g p_{f, i, m}^{t}$ using technology $m$ at node $i$ in period $t$. The variable $\eta_{f, i}^{t}$ is also matched with condition (6), which establishes the balance between the quantity of electricity produced $g p_{f, i, m}^{t}$ and sold $g_{f, i}^{t}$. Finally, (5) indicates that scarcity rent $\nu_{f, i, m}^{t}$ is positive when plants $m$ are run at their full capacity $G_{f, i, m}$.

$$
\begin{gathered}
0 \leq-p_{i}^{t}+\eta_{f, i}^{t} \perp g_{f, i}^{t} \geq 0 \\
0 \leq \operatorname{cost}_{f, i, m}+e m_{m} \cdot \lambda+\nu_{f, i, m}^{t}-\eta_{f, i}^{t} \perp g p_{f, i, m}^{t} \geq 0 \\
0 \leq G_{f, i, m}-g p_{f, i, m}^{t} \perp \nu_{f, i, m}^{t} \geq 0 \\
0 \leq \sum_{m} g p_{f, i, m}^{t}-g_{f, i}^{t} \perp \eta_{f, i}^{t} \geq 0
\end{gathered}
$$

Households and industries maximize their surplus. Conditions (7), (8) and (10) state that prices $p_{i}^{t}$ should be lower than the marginal willingness to pay for the first power unit if the quantities consumed $\left(d_{i}^{s, 1}, d_{i}^{w, 1}\right.$ and $\left.d_{i}^{t, 2}\right)$ are positive. The electricity consumption of households is $d_{i}^{t, 2}$. It differs per node $i$ and period $t$. Industrial electricity consumption is, instead, constant over time. In order to model this assumption, we first split electricity demand and the related electricity prices in sub-variables (respectively $d_{i}^{s, 1}, d_{i}^{w, 1}$ and $p_{i}^{s}, p_{i}^{w}$ ) accounting explicitly for the two periods presented in the model. We then add (9) to impose the equality between hourly summer (s) and winter (w) consumption. This condition is matched with the dual variable $\alpha_{i}$, which affects consumers' electricity prices as indicated in conditions (7) and (8). Electricity prices $p_{i}^{t}$ are identical among consumer segments in perfect competition.

$$
\begin{gathered}
0 \leq p_{i}^{s}-\alpha_{i}-a_{i}^{s, 1}+b_{i}^{s, 1} \cdot d_{i}^{s, 1} \cdot \perp d_{i}^{s, 1} \geq 0 \\
0 \leq p_{i}^{w}+\alpha_{i}-a_{i}^{w, 1}+b_{i}^{w, 1} \cdot d_{i}^{w, 1} \cdot \perp d_{i}^{w, 1} \geq 0 \\
0 \leq d_{i}^{s, 1}-d_{i}^{w, 1} \perp \alpha_{i} \geq 0 \\
0 \leq p_{i}^{t}-a_{i}^{t, 2}+b_{i}^{t, 2} \cdot d_{i}^{t, 2} \cdot \perp d_{i}^{t, 2} \geq 0
\end{gathered}
$$

Electricity is a special commodity since it is not storable. Real-time equality of electricity production and consumption is necessary for the well-functioning of physical system. This implies that generation flows need to be balanced each hour. This balance is expressed by equality (11). The associated hub price $p h u b^{t}$ is supposed to assume positive values.

$$
0 \leq \sum_{f, i} g_{f, i}^{t}-\sum_{i} d_{i}^{t, 1}-\sum_{i} d_{i}^{t, 2} \perp p h u b^{t} \geq 0
$$

$p h u b^{t}$ represents the market clearing price set at the hub node ${ }^{19}$ in each period $t$ and it is used to compute nodal electricity prices as shown in condition (12). Following nodal pricing theory, nodal electricity prices $p_{i}^{t}$ are given by the price at the $p h u b^{t}$ plus the congestion charges $\left(\sum_{m}\left(-\mu_{l}^{t,+}+\mu_{l}^{t,-}\right) \cdot P T D F_{l, i}\right)$ that consumers pay to the TSO. The regulation of the system implies that the generator receives and the consumer pays nodal prices. The result is that consumers situated in the hub node only pay the hub price and do not face the

\footnotetext{
${ }^{19}$ The hub node is supposed to be a virtual market where all electricity asks and bids converge and match.
} 
network costs. Last but not the least, the dual $\mu_{l}^{t}=-\mu_{l}^{t,+}+\mu_{l}^{t,-}$ can assume a positive or a negative sign, depending on the direction of the flow that congests the line. Nodal prices are then written as:

$$
0 \leq p_{i}^{t}-p h u b^{t}-\sum_{m}\left(-\mu_{l}^{t,+}+\mu_{l}^{t,-}\right) \cdot P T D F_{l, i} \perp \quad p h u b^{t} \geq 0
$$

Transmission costs affect electricity price making them different over nodes as soon as one line is congested in the system. Conditions (13) and (14) describe the transmission constraints in accordance with the DC load flow approximation. To this aim we use the Power Transfer Distribution Factor (PTDF) matrix, which determines both the patterns and the proportions of power flowing through network lines. $P T D F_{l, i}$ is the flow through line $l$ resulting from a unit injection in node $i$ and withdrawal at the hub (assuming no losses). A basic security constraint is that the flows in the lines do not exceed their capacities. This is expressed as follows. The sum over all nodes $i$ of the proportion of the net power flow $\left(\sum_{f} g_{f, i}^{t}-d_{i}^{t, 1}-d_{i}^{t, 2}\right)$ injected from all nodes $i$ and passing through line $l$ to reach the hub minus the sum over all nodes $i$ of the proportion of the net power flows injected from the hub and withdrawn from node $i$ must be lower than the capacity of the line Linecap $_{l}$ used to transfer electricity ${ }^{20}$. This must hold for any load pattern. We must therefore introduce two transmission constraints to account for the double direction that power flows can follow.

$$
\begin{aligned}
& 0 \leq \text { Linecap }_{l}-\left(\sum_{i} P T D F_{l, i} \cdot\left(\sum_{f} g_{f, i}^{t}-d_{i}^{t, 1}-d_{i}^{t, 2}\right)\right) \perp \mu_{l}^{t,+} \geq 0 \\
& 0 \leq \text { Linecap }_{l}+\left(\sum_{i} P T D F_{l, i} \cdot\left(\sum_{f} g_{f, i}^{t}-d_{i}^{t, 1}-d_{i}^{t, 2}\right)\right) \perp \mu_{l}^{t,-} \geq 0
\end{aligned}
$$

Relation (13) and (14) together with (12) express the market clearing conditions of a perfectly competitive transmission market organized according to the nodal paradigm.

The emission constraint (15) expresses that the total amount of emission produced over the year (hourly generation $g_{f, i, m}^{t}$ time the hour in each period $h_{\text {our }}^{t}$ and the emission factor $\mathrm{em}_{m}$ per technology $m$ ) can not exceed the annual emission cap $E$. The value of the permit price $\lambda$ is positive when the total amount of emissions generated equals the cap $E$. This means that the emission policy is binding. This opportunity cost influences electricity prices and firms' market optimality conditions (see 4). We recall that, in order to simplify the presentation, we model a closed allowance market restricted to the power sector. This implies that the emission cap $E$ is exactly equal to the sum of the allowances that electricity generating companies have so far received for free.

$$
0 \leq E-\sum_{t, f, i, m} g_{f, i, m}^{t} \cdot e m_{m} \cdot \text { hour }_{i}^{t} \perp \lambda \geq 0
$$

\footnotetext{
${ }^{20}$ We do not model here the so-called "n-1 reliability criterion". It ensures that in case a line is cut off, the remaining available lines can bear the redistributed flows without damaging the system security.
} 


\section{Appendix A.2. Single average cost pricing model}

In the single average cost pricing scenario, we assume that industries constitute a power purchase consortium that buys electricity from plants located in different nodes of the network, using special contracts. In this way, they face an identical price independently of their location. This model requires to introduce a market segmentation to correspond to the two different pricing schemes: marginal cost pricing for households and small industrial consumers (hereafter households), average cost pricing for large industrial consumers (hereafter industry). The apexes "1" and "2" are adopted to indicate respectively large industries and households' variables. Moreover, since industrial electricity consumption is constant, we assume that variables do not depend on time $t$. Because households consume more electricity in winter than in summer, we maintain the time dependence in their variables.

$$
0 \leq \eta_{f, i}^{t, 2}-p_{i}^{t, 2} \perp g_{f, i}^{t, 2} \geq 0
$$

$$
0 \leq \eta_{f, i}^{1}-\beta^{1}-\left(\sum_{t, l}\left(-\mu_{l}^{t,+}+\mu_{l}^{t,-}\right) \cdot \text { proportion }^{t} \cdot \operatorname{PTDF}_{l, i}\right) \perp g_{f, i}^{1} \geq 0
$$

Like in the reference model of Appendix A.1, power companies maximize their profits under generation and capacity constraints. The interpretation of conditions (16), (17), (18), (19), (20) and (21) is identical to those presented in Appendix A.1. Specifically, it implies that the operations of the part of the generation system allocated to industrial demand is efficient: it minimizes total costs among plants, taking into account transmission charges (the $\mu_{l}^{t, \pm}$ that have to be paid). In this interpretation $\beta^{1}$ is the marginal cost (at the hub) of electricity generated by the capacities dedicated to the industries. By construction, power companies differentiate their production activities between households and industry. This requires to duplicate the representation of the power sector. Moreover, generators have to decide how to share the installed capacity between small and large consumers. Variables $\eta_{f, i}^{t, 2}$ and $\eta_{f, i}^{1}$ are the marginal production cost faced by power companies to supply respectively households and industries; while $g_{f, i}^{t, 2}, g_{f, i}^{1}$ and $g p_{f, i, m}^{t, 2}, g p_{f, i, m}^{1}$ define respectively the amount of electricity sold to and produced for small and industrial consumers.

$$
\begin{gathered}
0 \leq \operatorname{cost}_{f, i, m}+\lambda \cdot e m_{m}+\nu_{f, i, m}^{t, 2}-\eta_{f, i}^{t, 2} \perp g p_{f, i, m}^{t, 2} \geq 0 \\
0 \leq \operatorname{cost}_{f, i, m}+\lambda \cdot e m_{m}+\nu_{f, i, m}^{1}-\eta_{f, i}^{1} \perp g p_{f, i, m}^{1} \geq 0 \\
0 \leq \sum_{m} g p_{f, i, m}^{t, 2}-g_{f, i}^{t, 2} \perp \eta_{f, i}^{t, 2} \geq 0 \\
0 \leq \sum_{m} g p_{f, i, m}^{1}-g_{f, i}^{1} \perp \eta_{f, i}^{1} \geq 0
\end{gathered}
$$

The split of capacity is endogenously determined by constraints (22) and (23). Variables $G_{f, i, m}^{2}$ and $G_{f, i, m}^{1}$ indicate the plant capacities respectively dedicated to households and industries. Condition (24) states that the sum of the MW 
capacity reserved for households and industries should not exceed the total power capacity $\left(G_{f, i, m}\right)$ installed in the market.

$$
\begin{gathered}
0 \leq G_{f, i, m}^{2}-g p_{f, i, m}^{t, 2} \perp \nu_{f, i, m}^{t, 2} \geq 0 \\
0 \leq G_{f, i, m}^{1}-g p_{f, i, m}^{1} \perp \nu_{f, i, m}^{1} \geq 0 \\
0 \leq G_{f, i, m}-G_{f, i, m}^{1}-G_{f, i, m}^{2} \perp \gamma_{f, i, m} \geq 0
\end{gathered}
$$

That constraint is matched with the variable $\gamma_{f, i, m}$ representing the global scarcity rent. The variable $\gamma_{f, i, m}$ together with the variables $\nu_{f, i, m}^{t, 2}$ and $\nu_{f, i, m}^{1}$ appearing in (25) and (26) ensure the effectiveness of the split in capacity between the two consumer sectors. Note first that the parameter proportion ${ }^{t}$ in (25) determines the proportions of the duration of each period $t$. Looking at conditions (25) and (26), one then notices that $\gamma_{f, i, m}$ implicitly defines an equality between $\nu_{f, i, m}^{t, 2}$ and $\nu_{f, i, m}^{1}$. (25) and (26) therefore imply that the marginal value of capacity are identical for households and industrial consumers, even if their electricity prices are determined using two different approaches. This implies that the allocation of the capacity maximizes its total value.

$$
\begin{gathered}
0 \leq \gamma_{f, i, m}-\sum_{t} \nu_{f, i, m}^{t, 2} \cdot \text { proportion }^{t} \perp G_{f, i, m}^{2} \geq 0 \\
0 \leq \gamma_{f, i, m}-\nu_{f, i, m}^{1} \perp G_{f, i, m}^{1} \geq 0
\end{gathered}
$$

The efficiency of the capacity allocation can also be observed on the variable $\beta^{1}$ that is meant to represent the hypothetical marginal cost price that industries should pay, at the hub, under a perfectly competitive regime. Empirical results show that its value $(54.10 € / \mathrm{MWh})$ corresponds exactly to the average of the $p h u b^{t, 2}$ on the households' market weighted by period duration. It is worthwhile to explain that the industrial consumers' problem effectively embeds two different pricing structures. One is real in the sense that it corresponds to the commercial transactions (what the industry pay to the generators and the TSO). The other is virtual in the sense of transfer price. It is there just to insure efficient internal operations of the capacities dedicated to the industry. An average cost price $p^{1}$ (see (35)), including the average production and transmission costs is what is effectively paid for electricity trading. In contrast, the marginal cost price $\beta^{1}$ that pairs the electricity balance of the industrial sector plays the role of an internal transfer price. The similarity can be seen by first observing the relations. This dual price $\beta^{1}$ appears also in condition (17) and (plus the transmission charges) assume the role of $p_{i}^{t, 2}$ for households.

$$
\begin{gathered}
0 \leq \sum_{f, i} g_{f, i}^{t, 2}-\sum_{i} d_{i}^{t, 2} \perp p h u b^{t, 2} \geq 0 \\
0 \leq \sum_{f, i} g_{f, i}^{1}-\sum_{i} d_{i}^{1} \perp \beta^{1} \geq 0
\end{gathered}
$$

(27) expresses the market clearing at the hub of electricity delivered to households. This condition implies the hub price $p h u b^{t, 2}$, which is used to compute their marginal electricity prices $p_{i}^{t, 2}$ (see condition (30)) as already explained in the reference model. (28) expresses a similar virtual market clearing price for the electricity delivered to the industry. 


$$
\begin{gathered}
0 \leq p_{i}^{t, 2}-a_{i}^{t, 2}+b_{i}^{t, 2} \cdot d_{i}^{t, 2} \perp d_{i}^{t, 2} \geq 0 \\
0 \leq p_{i}^{t, 2}-p h u b^{t, 2}-\left(\sum_{l}\left(-\mu_{l}^{t,+}+\mu_{l}^{t,-}\right) \cdot P T D F_{l, i}\right) \perp p_{i}^{t, 2} \geq 0 \\
0 \leq p^{1}-a_{i}^{1}+b_{i}^{1} \cdot d_{i}^{1} \perp d_{i}^{1} \geq 0
\end{gathered}
$$

Conditions (29) and (31) express the inverse electricity demand functions of the two consumer sectors. Note that industries in (31) globally face the average price $p^{1}$, but they pay pprod $^{1}$ to power companies and $\operatorname{ptrans}^{1}$ to the TSO. Equations (32) and (33) illustrate the formulation of these two components of the single average cost price. The average production cost accounts for the total variable $\left(\operatorname{cost}_{f, i, m}\right.$ (fuel) and $\mathrm{em}_{m} \cdot \lambda$ (emission)) costs and the annual fixed charges $F C_{f, i, m}$ related to capacity $G_{f, i, m}^{1}$ they have under their direct control. The value 8760 is the number of hours in one year.

$$
\begin{gathered}
0 \leq \operatorname{pprod}^{1}-\frac{\left(\sum_{f, i, m}\left(g p_{f, i, m}^{1} \cdot\left(\operatorname{cost}_{f, i, m}+e m_{m} \cdot \lambda\right) \cdot 8760\right)\right)}{\sum_{i} d_{i}^{1} \cdot 8760}+ \\
-\frac{\sum_{f, i, m} F C_{f, i, m} \cdot G_{f, i, m}^{1}}{\sum_{i} d_{i}^{1} \cdot 8760} \perp \operatorname{pprod}^{1} \geq 0
\end{gathered}
$$

The average transmission costs accounts for the congestion burdens caused by flows $i n j_{i}$ exchanged among industries.

$$
\begin{gathered}
0 \leq \text { ptrans }^{1}+ \\
-\frac{\left(\sum_{l, i} P T D F_{l, i} \cdot i n j_{i} \cdot 8760 \cdot \sum_{t}\left(\mu_{l}^{t,+}-\mu_{l}^{t,-}\right) \cdot \text { proportion }^{t}\right)}{\sum_{i} d_{i}^{1} \cdot 8760} \perp \text { prans }^{1} \geq 0 \\
0 \leq i n j_{i}-\left(\sum_{f} g_{f, i}^{1}-d_{i}^{1}\right) \perp i n j_{i} \geq 0 \\
0 \leq p^{1}-\text { pprod }^{1}-\text { ptrans }^{1} \perp p^{1} \geq 0
\end{gathered}
$$

Finally, the transmission (36) and (37) and the emission (38) constraints slightly change with respect to reference case in the sense that injection and generation variables are disaggregated into households and industries' components. This is a direct implication of the market segmentation introduced to accommodate the two pricing regimes. However, the structure of these relations remains unchanged.

$$
\begin{aligned}
& 0 \leq \text { Linecap }_{l}-\left(\sum_{i} P T D F_{l, i} \cdot\left(\sum_{f} g_{f, i}^{1}+\sum_{f} g_{f, i}^{t, 2}-d_{i}^{1}-d_{i}^{t, 2}\right)\right) \perp \mu_{l}^{t,+} \geq 0 \\
& 0 \leq \operatorname{Linecap}_{l}+\left(\sum_{i} P T D F_{l, i} \cdot\left(\sum_{f} g_{f, i}^{1}+\sum_{f} g_{f, i}^{t, 2}-d_{i}^{1}-d_{i}^{t, 2}\right)\right) \perp \mu_{l}^{t,-} \geq 0 \\
& 0 \leq E-\left(\sum_{f, i, m} e m_{m} \cdot g p_{f, i, m}^{1} \cdot 8760+\sum_{t, f, i, m} e m_{m} \cdot g p_{f, i, m}^{t, 2} \cdot \operatorname{hour}^{t}\right) \perp \lambda \geq 0
\end{aligned}
$$




\section{Appendix A.3. Nodal average cost pricing}

We extend the single average cost pricing approach to the case when industrial consumers can conclude special contracts with local producers. In this way, we get a new price formation reflecting nodal average costs. This implies different average cost prices (see condition (39)), depending on the technology employed to generate power at each node. Transmission costs are no longer embedded in the nodal average prices, since there is a direct local connection between industries and generating companies. We assume, in fact, that industrial consumers are supplied only with electricity produced by local power plants dedicated to them. In other words, there is no need to import electricity in order to satisfy the internal industrial demand. Nevertheless, industries remain subject to the various local constraints, which unavoidably affects their electricity prices. Nodal average cost prices $p_{i}^{1}$ vary over nodes $i$ and account for the fuel $\left(\operatorname{cost}_{f, i, m}\right)$, the emission $\left(e m_{m} \cdot \lambda\right)$ and the capacity charges $\left(F C_{f, i, m}\right)$ associated with the plants $m$ that power firm $f$ dedicates to industries in node $i$. Globally the capacity reserved for industrial consumers is $G_{f, i, m}^{1}$. This leads to the expression:

$$
\begin{gathered}
0 \leq p_{i}^{1}-\frac{\left(\sum_{f, m}\left(g p_{f, i, m}^{1} \cdot\left(\operatorname{cost}_{f, i, m}+e m_{m} \cdot \lambda\right) \cdot 8760\right)\right)}{d_{i}^{1} \cdot 8760}+ \\
-\frac{\sum_{f, m} F C_{f, i, m} \cdot G_{f, i, m}^{1}}{d_{i}^{1} \cdot 8760} \perp p_{i}^{1} \geq 0
\end{gathered}
$$

All the other assumptions (notably market segmentation and capacity splitting) and the corresponding constraints still hold. Furthermore, the households' optimization problem does not change. For these reasons, we consider only the complementarity conditions that are subject to modifications. Since the industrial market is local, in each node there is an industrial energy balance as shown by condition (40). As a consequence, the dual variable $\beta_{i}^{1}$ depends on node $i$.

$$
0 \leq \sum_{f} g_{f, i}^{1}-d_{i}^{1} \perp \beta_{i}^{1} \geq 0
$$

As in the single average cost pricing model, $\beta_{i}^{1}$ is the virtual price (equal to the local marginal cost) that industries would have to pay in a perfectly competitive market if demand were the one generated by $p_{i}^{t, 2}$, the small consumers' prices.

\begin{tabular}{|l|c|c|}
\hline$€ /$ MWh & $p_{i}^{t, 2}$ & $\beta_{i}^{1}$ \\
\hline \hline Germany & 50.63 & 50.63 \\
\hline France & 54.01 & 54.01 \\
\hline Merchtem & 52.43 & 52.43 \\
\hline Gramme & 52.59 & 52.59 \\
\hline Krimpen & 51.99 & 51.99 \\
\hline Maastricth & 51.94 & 51.94 \\
\hline Zwolle & 51.63 & 51.63 \\
\hline
\end{tabular}

Table 12: Comparison between $p_{i}^{t, 2}$ (weighted average) and $\beta_{i}^{t, 1}$ 
In other words, $\beta_{i}^{1}$ is an internal transfer price which effectively ensures the right allocation of the market sources between households and industries. Our empirical tests show that $\beta_{i}^{1}$ and the weighted (by period duration) average values of $p_{i}^{t, 2}$ are identical (see Table 12). This equality between the virtual transfer price and the one paid by the households confirms the efficiency of the allocation of capacity between the two sectors. At each node, the two market segments pay the same price: this means that the marginal welfare in the two segments are equal at each node. The price $\beta_{i}^{1}$ appears also in (42) which states the equality between marginal electricity price and cost for positive generation level $g_{f, i}^{1}$. Condition (41) is the new demand function of industrial consumers. Finally, transmission constraints are slightly different from (36) and (37) presented in Appendix A.2. By construction, network congestion is here only caused by power flows exchanged among households. For this reason, the injection flows in conditions (43) and (44) are computed accounting only for the electricity produced for and demanded by small consumers.

$$
\begin{gathered}
0 \leq p_{i}^{1}-a_{i}^{1}+b_{i}^{1} \cdot d_{i}^{1} \perp d_{i}^{1} \geq 0 \\
0 \leq \eta_{f, i}^{1}-\beta_{i}^{1} \perp g_{f, i}^{1} \geq 0 \\
0 \leq \operatorname{Linecap}_{l}-\left(\sum_{i} P T D F_{l, i} \cdot\left(\sum_{f} g_{f, i}^{t, 2}-d_{i}^{t, 2}\right)\right) \perp \mu_{l}^{t,+} \geq 0 \\
0 \leq \operatorname{Linecap}_{l}+\left(\sum_{i} \operatorname{PTDF}_{l, i} \cdot\left(\sum_{f} g_{f, i}^{t, 2}-d_{i}^{t, 2}\right)\right) \perp \mu_{l}^{t,-} \geq 0
\end{gathered}
$$




\section{Appendix B. Input Data}

Table 13 introduces the reference demand values per period and consumer group. Our computations are based on public data make available on Eurostat (see [5]) and UTCE websites (see $[15,16]$ ).

\begin{tabular}{|l|r|r|r|r|}
\hline Nodes & \multicolumn{2}{|c|}{ Off-peak } & \multicolumn{2}{|c|}{ Peak } \\
\hline \hline Reference Demand & Industry & Households & Industry & Households \\
\hline \hline Germany & 38,400 & 14,660 & 38,400 & 43,230 \\
\hline France & 26,530 & 25,410 & 26,530 & 53,380 \\
\hline Merchtem (BE) & 4,770 & 1,310 & 4,770 & 4,580 \\
\hline Gramme (BE) & 2,050 & 560 & 2,050 & 1,960 \\
\hline Krimpen (NL) & 4,300 & 2,560 & 4,300 & 6,240 \\
\hline Maastricht (NL) & 950 & 570 & 950 & 1,390 \\
\hline Zwolle (NL) & 1,570 & 930 & 1,570 & 2,280 \\
\hline
\end{tabular}

Table 13: Hourly reference demand in MW

Each generating company considered in our models has its own technology structure as indicated in Table 14.

\begin{tabular}{|l|r|r|r|r|r|r|r|}
\hline \multicolumn{7}{|c|}{ Available Capacity } \\
\hline \hline Technology & Germany & France & Merchtem & Gramme & Krimpen & Maastricht & Zwolle \\
\hline \hline Hydro & 1,505 & 6,804 & 0 & 13 & 0 & 0 & 0 \\
\hline Wind & 4,583 & 1 & 20.43 & 21.32 & 101.26 & 101.26 & 102 \\
\hline Nuclear & 15,007 & 45,369 & 2,078 & 2,204 & 337 & 0 & 0 \\
\hline Lignite & 17,783 & 77 & 0 & 0 & 0 & 0 & 0 \\
\hline Coal & 24,613 & 8,824 & 1,564 & 979 & 3,128 & 0 & 482 \\
\hline CCGT & 13,544 & 8,164 & 2,589 & 1,207 & 4,432 & 2,917 & 4,834 \\
\hline Other-Gas & 2,147 & 256 & 194 & 170 & 833 & 0 & 0 \\
\hline Oil-based & 0 & 4,760 & 55 & 194 & 0 & 0 & 0 \\
\hline \hline total & $\mathbf{7 9 , 1 8 3}$ & $\mathbf{7 3 , 5 3 5}$ & $\mathbf{6 , 5 0 0}$ & $\mathbf{4 , 7 8 8}$ & $\mathbf{8 , 8 3 1}$ & $\mathbf{3 , 0 1 8}$ & $\mathbf{5 , 4 1 7}$ \\
\hline
\end{tabular}

Table 14: MW of available capacity by nodes

\begin{tabular}{|l|c|c|c|}
\hline Technology & Emission Factor & Marginal cost & Availability \\
\hline \hline Hydro & 0 & 0.00 & different \\
\hline Wind & 0 & 0.00 & $25 \%$ \\
\hline Nuclear & 0 & 4.50 & $75 \%$ \\
\hline Lignite & 0.97 & 14.86 & $85 \%$ \\
\hline Coal & 0.9542 & 21.62 & $80 \%$ \\
\hline CCGT & 0.432 & $36.35-37.08$ & $85 \%$ \\
\hline Other-Gas & 0.6266 & $54.92-55.20$ & $85 \%$ \\
\hline Oil-based & 0.8441 & $46.9-67.62$ & $85 \%$ \\
\hline
\end{tabular}

Table 15: Emission factors (ton/MWh), Marginal costs (€/MWh) and Availability factors per technology

The hydro factors adopted in the model are based on own computations and they are as follows: $32.4 \%$ (Germany), 28.9\% (France), 12.3\% (Belgium) and 0\% (The 
Netherlands). We used public data available on Eurostat [6] and UTCE [15] websites. The starting values of the installed capacity are based on information published on the annual reports (2005) of the generating companies included in the simulations. Table 15 reports all the emission rates (see also [1] for more details). The marginal fuel costs are computed taking into account the efficiency factor of each technology. They are based on public data ${ }^{21}$. In particular, we set the efficiency rates of lignite/coal and CCGT plants respectively at $37 \%$ and $49 \%$ as in [18]. Table 16 lists the amount of emission allowances that each electricity generating companies holds. Those define their emissions cap. As reference, we took public figures available on the European Commission website (see [5]).

\begin{tabular}{|l|r|r|r|r|r|}
\hline Ton p.a. & Germany & France & Belgium & Netherlands & Per Company \\
\hline \hline EoN & $35,798,149$ & & & $7,698,528$ & $\mathbf{4 3 , 4 9 6 , 6 7 7}$ \\
\hline Electrabel & 351,107 & & $9,296,495$ & $7,749,596$ & $\mathbf{1 7 , 3 9 7 , 1 9 8}$ \\
\hline Edf & & $23,540,828$ & & & $\mathbf{2 3 , 5 4 0 , 8 2 8}$ \\
\hline EnBW & $10,302,328$ & & & & $\mathbf{1 0 , 3 0 2 , 3 2 8}$ \\
\hline Essent & & & & $9,909,033$ & $\mathbf{9 , 9 0 9 , 0 3 3}$ \\
\hline Nuon & & & & $9,109,160$ & $\mathbf{9 , 1 0 9 , 1 6 0}$ \\
\hline RWE & $112,482,413$ & & & & $\mathbf{1 1 2 , 4 8 2 , 4 1 3}$ \\
\hline Vattenfall & $77,003,200$ & & & & $\mathbf{7 7 , 0 0 3 , 2 0 0}$ \\
\hline Fringe & $72,384,875$ & $11,709,252$ & $5,764,115$ & $4,283,146$ & $\mathbf{9 4 , 1 4 1 , 3 8 8}$ \\
\hline \hline tot & $\mathbf{3 0 8 , 3 2 2 , 0 7 2}$ & $\mathbf{3 5 , 2 5 0 , 0 8 0}$ & $\mathbf{1 5 , 0 6 0 , 6 1 0}$ & $\mathbf{3 8 , 7 4 9 , 4 6 3}$ & $397,382,225$ \\
\hline
\end{tabular}

Table 16: NAPs per generating companies and country

Finally, Tables 17 shows the hourly fixed costs included in the average cost pricing models. They are classified by node and technology. In accordance with our input data (see [8]), "wind" technologies are more expensive in the Netherlands than in the other countries, where power companies receive subsidies to build "wind" plants.

\begin{tabular}{|l|r|r|r|r|r|r|r|}
\hline$€ / M W h$ & Germany & France & Merchtem & Gramme & Krimpen & Maastricht & Zwolle \\
\hline \hline Hydro & 55.71 & 55.71 & 55.71 & 55.71 & 55.71 & 55.71 & 55.71 \\
\hline Wind & 46.07 & 41.93 & 41.93 & 41.93 & 86.81 & 86.81 & 86.81 \\
\hline Nuclear & 14.68 & 12.89 & 12.89 & 12.89 & 17.76 & 17.76 & 17.76 \\
\hline Lignite & 12.55 & 11.03 & 12.55 & 12.55 & 12.55 & 12.55 & 12.55 \\
\hline Coal & 12.55 & 11.03 & 12.55 & 12.55 & 12.55 & 12.55 & 12.55 \\
\hline CCGT & 4.16 & 4.96 & 7.93 & 7.93 & 8.53 & 8.53 & 8.53 \\
\hline Natural gas & 4.16 & 4.95 & 7.92 & 7.92 & 8.52 & 8.52 & 8.52 \\
\hline Oil-based & 4.16 & 4.96 & 7.93 & 7.93 & 8.53 & 8.53 & 8.53 \\
\hline
\end{tabular}

Table 17: Hourly fixed costs per node and technology

\footnotetext{
${ }^{21}$ Sources: IEA, Weighted Average CIF Cost of Crude Oil, IEA Annual Statistical Supplement for 2005, released August, 25 2006. www.bafa.de/1/de/service/statistiken/kraftwerkssteinkohle.php; www.bmwi.de/BMWi/Navigation/Energie/Energiestatistiken/energiestatistiken, did = 53736.html;

EWI/Prognos Studie: Die Entwicklung der Energiemrkte bis zum Jahr 2030, p. 12.
} 